\title{
Being "in" or "out" of the game: subjective and acoustic reactions to exclusion and popularity in social anxiety
}

\author{
Eva Gilboa-Schechtman ${ }^{1}$, Lior Galili ${ }^{1}$, Yair Sahar ${ }^{1}$ and Ofer Amir ${ }^{2}$ \\ ${ }^{1}$ Department of Psychology and the Gonda Multidisciplinary Brain Research Center, Bar-Ilan University, Ramat Gan, Israel \\ ${ }^{2}$ Department of Communication Disorders, Sackler Faculty of Medicine, Tel Aviv University, Tel Aviv, Israel
}

\author{
Edited by: \\ Alexandre Heeren, Université \\ Catholique de Louvain, Belgium \\ Reviewed by: \\ Pierre Maurage, Université \\ Catholique de Louvain, Belgium \\ Mariella Pazzaglia, University of \\ Rome "La Sapienza," Italy \\ *Correspondence: \\ Eva Gilboa-Schechtman, \\ Department of Psychology and the \\ Gonda Multidisciplinary Brain \\ Research Center, Bar-llan University, \\ Building 901, Ramat Gan 52900, \\ Israel \\ e-mail: evagillboa@gmail.com
}

Social Anxiety (SA) has been shown to be associated with compensatory deficits in pro-social behavior following exclusion and with failure to capitalize on social success. We assessed the subjective and expressive responses of high $(n=48)$ and low $(n=56)$ socially anxious individuals to exclusion, acceptance, and popularity induced by a participation in an online ball-tossing game. Before the manipulation, participants read aloud neutral and command utterances. Following the manipulation, participants rated their mood and cognitions and re-read the utterances. Acoustic properties (fundamental frequency-mF0, vocal intensity) of these utterances were analyzed. We found greater differences in self-esteem between high and low socially anxious individuals following the exclusion condition, as compared to the acceptance condition. Among low socially anxious individuals, exclusion promoted increased vocal confidence, as indicated by decreased $\mathrm{mFO}$ and increased vocal intensity in uttering commands; High socially anxious individuals exhibited an opposite reaction, responding to exclusion by decreased vocal confidence. Following popularity, high SA was associated with decreased enhancement in mood and self-esteem in women but not in men. Consistent with evolutionary and interpersonal accounts of SA, we highlight the importance of examining the effects of SA and gender on events indicating unambiguous and unanimous social acceptance. Examining reactivity to changes in belongingness may have important implications for understanding the core mechanisms of SA.

Keywords: social phobia, rejection, acceptance, self-esteem, dominance, social rank, acoustic analysis, voice

\section{INTRODUCTION}

Social Anxiety disorder (SAD, or social phobia) is a condition involving marked anxiety about social or performance situations in which there is a fear of embarrassing oneself under scrutiny by others (DSM-IV, American Psychiatric Association, 2000). SAD often has its onset in childhood and tends to precede most other disorders with which it is co-morbid, most notably depression (Bittner et al., 2004). SAD is associated with severe psychological, interpersonal, and professional consequences (e.g., Ruscio et al., 2008). Given these anxieties and avoidances, it is not surprising that socially anxious individuals report high levels of negative affect, and functional impairment in several life areas (Aderka et al., 2012). Unsurprisingly, SAD is also associated with lower wellbeing (Sherbourne et al., 2010) and lower levels of positive affect (e.g., Kashdan, 2007). These findings have frequently been related to the impairment in interpersonal connectedness common in SAD (e.g., Gilboa-Schechtman et al., 2013a,b).

Most theoretical models of social anxiety (SA) consider heightened sensitivity, enhanced responsivity, and impaired affective regulation in the face of social threat to be at the epicenter of this condition (e.g., Clark and Wells, 1995; Rapee and Heimberg, 1997; Gilbert and Trower, 2001; Hofmann et al., 2004). During human evolutionary history, loss of belongingness was associated with threat to survival (Wesselmann et al., 2012a,b). Accordingly, the human tendency to belong and affiliate is frequently defined as one of the most essential and fundamental needs (e.g., Baumeister and Leary, 1995). Given the centrality of belongingness, basic psychological systems are postulated to monitor for changes in social inclusion and exclusion. Sensitivity to changes in belongingness is frequently explained in evolutionary terms: being a member of a group improves survival chances due to the protection and resources offered by the group (Lancaster, 1986). Relatedly, positive affect experienced in response to social acceptance is likely to strengthen one's psychological resilience (Fredrickson et al., 2003), to promote physical health (e.g., Davidson et al., 2010; Boehm and Kubzansky, 2012), and to increase longevity (Xu and Roberts, 2010).

Consistent with these theoretical postulations, social exclusion has been found to provoke significant changes across multiple psychobiosocial domains. It has been found to engender subjective experience of distress (Van Beest and Williams, 2006), behavioral dysregulation (Oaten et al., 2008), changes in cognitive efficiency (Hess and Pickett, 2010), changes in attentional focus (Dewall et al., 2009), enhanced blood pressure (Stroud et al., 2000), cortisol reactivity (Blackhart et al., 2007) and enhanced activation in brain regions that process and regulate the unpleasantness of physical pain (Eisenberger et al., 2003). The salubrious effects of social acceptance are also robust. Social acceptance is associated with changes in mood, self-esteem, behavior and physiology (e.g., Leary et al., 2001; Mendes et al., 2008; DeWall 
et al., 2010). Yet, given the centrality of the belongingness system, its implications to psychopathology in general, and to SA in particular, have not been thoroughly explored. This is the main theme of the present research.

SA is postulated to function as a warning system that alerts people to potential threats to their belongingness status (Leary and Kowalski, 1995; DeWall et al., 2011). Indeed, it has been found that socially anxious individuals are characterized by a high sensitivity to exclusion (Zadro et al., 2006). Specifically, Zadro and her colleagues found SA to be associated with more prolonged recovery following an exclusion manipulation. Using a similar exclusion paradigm, Oaten and colleagues found that individuals with high SA differ from individuals with low SA in their ability to self-regulate following exclusion (Oaten et al., 2008). Further, research in temperamentally shy children found more intense emotional upheaval and poorer vagal regulation in response to peer rejection (Gazelle and Druhen, 2009). Moreover, in a recent study with children, Reijntjes and colleagues found that SA was associated with greater changes in state self-esteem following peer disapproval (Reijntjes et al., 2011).

It appears that SA affects not only the quantitative, but also qualitative nature of coping with exclusion. While among lowsocially anxious individuals exclusion promoted renewed interest in connecting with sources of positive social interaction, highsocially anxious individuals failed to react to rejection in a prosocial manner and exhibited evidence of decreased social interaction effectiveness (Mallott et al., 2009). Specifically, Mallott and colleagues examined nonverbal characteristics of self-presentation of individuals high and low in SA following interpersonal rejection. They found that, observers' subjective ratings of vocal and eyegaze performance was inversely related to SA. In the present study we sought to extend the investigation of the effects of changes in social belongingness, to include objective measures of vocal production. Acoustic analysis of speech is emerging as an indirect, noninvasive, and sensitive measure of emotional state (Elfenbein and Ambady, 2002; Juslin and Laukka, 2004) and interpersonal strategies (Bugental et al., 2009), in research as well as in clinical settings (Diamond et al., 2010).

Vocal parameters have been examined in an attempt to capture the emotional "tone" of the voice-that is the aspect of speech that is not conveyed through the meaning of verbal utterance. These nonverbal features of a spoken message (Tusing and Dillard, 2000) have been shown to play an important role in conveying emotions (Laukka and Elfenbein, 2011) and in conducting power negotiation (Scherer, 1986; Scherer et al., 2003). Vocal parameters are less controllable than are other types of nonverbal behaviors (Zuckerman et al., 1981) and therefore may serve as "honest signals" of the speaker's current emotional state (Bugental et al., 2009). The vocal parameters that have been most frequently used in past research are fundamental frequency $(\mathrm{mF} 0)$ and vocal intensity.

There is a robust line of research linking certain parameters of vocalization to social rank. Consistent with Ohala's (1982) evolutionary model, lower mF0 has been associated with enhanced dominance (e.g., Ohala, 1984; Puts et al., 2006, 2007; Jones et al., 2010). Vocal intensity is positively associated with dominance rating in the production of spontaneous speech (Tusing and Dillard,
2000). Moreover, these parameters were also shown to differentiate between vocal profiles of different intents (Galili et al., 2013). Specifically, as compared to neutral utterances, command utterances were characterized by increased $\mathrm{mF} 0$ and higher vocal intensity. Acoustic analysis has the potential to offer a subtle understanding of the ways in which individuals negotiate interpersonal interactions. Yet, acoustic analysis has, until recently, been under-utilized. We believe it offers a way to understand corrective actions people take following exclusion.

Measures of acoustic production show promise as indirect measures of SA (e.g., Laukka et al., 2008; Weeks et al., 2011, 2012; Galili et al., 2013). Specifically, analyzing the vocal properties of planned speech, we found that SA was associated with higher $\mathrm{mF0}$, and with decreased vocal intensity in men (Galili et al., 2013). Using spontaneous speech, Weeks and colleagues similarly found that clinical SA was associated with increased F0, and that this pattern was more pronounced in men than in women (Weeks et al., 2012). In addition, Laukka and colleagues found that among clinically socially anxious individual mF0 was decreased among treatment responders (Laukka et al., 2008). In view of these findings, the primary aim of the present study was to extend the research on reactivity to social exclusion in SA by including acoustic indices of interpersonally-directed utterances.

The second aim of this study was to examine the reactions of socially anxious individuals to events connoting social acceptance. While those events are commonly experienced as positive by nonsocially anxious individuals, this is not necessarily the case for socially anxious persons (e.g., Weeks and Howell, 2012). Several perspectives (e.g., Alden and Taylor, 2004; Weeks and Howell, 2012; Gilboa-Schechtman et al., 2013a,b) converge in suggesting that socially anxious individuals may exhibit biased processing of positive social attention. There is growing evidence indicating that socially anxious people were less successful at capitalizing on positive social experiences than are individuals without SA, even after controlling for depression (e.g., GilboaSchechtman et al., 2000; Kashdan et al., 2011; see also GilboaSchechtman et al., 2013a,b, for review). Exploring the nature of socially anxious individuals' reactions to events indicating social acceptance is likely to contribute to the greater understanding of core processes in SA.

The experimental research on the effects of positive social attention in SA has been limited. In a pioneering study, Alden and colleagues found that, upon receiving positive feedback following a social interaction, individuals with high levels of SA expected to experience greater levels of anxiety regarding a future social interaction (Alden et al., 2004). In addition, following the receipt of positive feedback, people with high levels of SA predicted that their partner would expect more from them in the next interaction, and that they would fall short of those expectations (Alden and Wallace, 1995; Wallace and Alden, 1997). Finally, Alden and colleagues found that the tendency to interpret positive social events as indicative of negative future outcomes partially mediated the relationship between SA and decreased positive affect (Alden et al., 2008). Importantly, in all of these studies success in a given interaction was found to bear on future interaction. But what if the "beam of social attention" was not specifically related to future occurrences? Does social visibility exert a "warm 
glow" for socially anxious and nonsocially anxious people alike? Addressing this question was the second aim of our study.

In the present study we assessed the subjective and expressive responses of individuals high and low in SA to exclusion, acceptance, and popularity induced by a participation in an online ball-tossing paradigm-Cyberball. Cyberball is one of the most commonly used procedures in investigating the effects of social exclusion (Williams, 1997, 2001, 2009). Previous Cyberball studies included two conditions: exclusion vs. acceptance (i.e., receiving a "fair share" of the throws). In the present study we introduced a third condition - popularity — in which participants received all the possible throws from the other two players.

Before beginning the Cyberball task, participants read aloud neutral, command and request utterances. Upon completing the Cyberball task, participants rated their mood and cognitions and re-read aloud the utterances. Subjective, cognitive, and acoustic measures ( $\mathrm{mF} 0$, vocal intensity) were analyzed.

Four hypotheses were examined. First, consistent with the enhanced exclusion-reactivity accounts, we postulated that as compared to low SA individuals, individuals high in SA would report lower mood and self-esteem following exclusion as compared to acceptance (enhanced exclusion reactivity hypothesis). Second, consistent with the impaired positivity account (GilboaSchechtman et al., 2013a,b), we postulated that, as compared to individuals low in SA, individuals high in SA would report lower mood and self-esteem following popularity as compared to the acceptance condition (impaired positivity hypothesis). Third, with respect to the acoustic parameters, consistent with the compensatory deficits view of SA, we postulated that exclusion (as compared to acceptance) would lead to more insecure (and less dominant) behaviors in individuals with low levels of SA, while individuals high in SA would not exhibit this pattern. Specifically, we expected to observe a greater increase in $\mathrm{mF} 0$ and a greater decrease in vocal intensity for command vs. neutral sentences in individuals high in SA, as compared to individuals low in SA (vocal insecurity following exclusion hypothesis). Fourth, we also expected that following popularity, individuals high in SA would exhibit a lesser increase in a pattern of confident vocal behavior as compared to individuals low in SA. Specifically, we expected a smaller decrease in $\mathrm{mF} 0$ and a smaller increase in vocal intensity for command vs. neutral utterances in individuals high in SA, as compared to individuals low in SA (vocal confidence following popularity hypothesis).

\section{METHODS \\ PARTICIPANTS}

Hundred and four university students (58 women) took part in the study in exchange for 30 NIS (equivalent to 8 US\$) or academic credit. Participants were recruited through the Bar-Ilan University Psychology Department Subject Pool, as well as from advertisements in billboards on campus and electronic forums. Before arrival to the laboratory, participants received several self-report questionnaires, including questionnaires assessing SA. Participants who scored below the accepted cut-off for clinical range or above the cut-off for diagnosis for SAD (Baer and Blais, 2010) on a self-assessment measure of SA (Fresco et al., 2001) were invited to participate in the study.

\section{PROCEDURE}

Participants were invited to take part in a study investigating individual differences in "visual perception and vocal production." Upon arrival to the laboratory and signing a consent form, participant met a confederate who was introduced as a fellow participant. Participants were introduced to the research purpose and procedure, and were photographed using a web camera for future use in the Cyberball task. Next, participants engaged in a first (pre-manipulation) vocal recording session.

Participants were then told that they will play an internet game "Cyberball" (see Williams et al., 2000) with two other students, one of whom they already met in the waiting room, and the other is waiting in an adjacent lab. Next, the experimenter made a staged phone call to the neighboring laboratory, informing that the participants (the confederate and the actual participant) are ready to start. Participants were randomly assigned to one of three conditions in the ball-tossing game: Exclusion, Acceptance, and Popularity. In all conditions, the game lasted approximately $5 \mathrm{~min}$.

Upon completion of the game, participants filled out the Basic Needs Threat Questionnaire (Zadro et al., 2004). Next, they performed the second (post-experimental) vocal recording session. Then, they took part in a brief $(3 \mathrm{~min})$ cognitive task not reported in the present study. All participants then completed several self-report questionnaires. Lastly, they were de-briefed by the experimenter about the real purpose of the experiment and its procedure. During the debriefing participants were interviewed about the believability of the experimental procedure. None expressed concerns or disbelief regarding the role of both co-participants.

\section{RECORDINGS}

Recording sessions were performed individually in a quiet room. The experimenter familiarized the participants with the equipment and remained present in the room during the entire recording session. During each recording session, the participants' voice was recorded while reading three different types of sentences: neutral ("Danny went to work with his dad" and "Chad helped us on the beach"), request ("Please open the window") and command ("Open the window immediately"). Participants were asked to read each sentence twice in a way consistent with their meaning. The sentences' order was randomized across participants. Participants' speech signals were recorded using a Sennheiser PC20 headset microphone (High Wycombe, United Kingdom). The microphone was positioned approximately $5 \mathrm{~cm}$ from the corner of the participant's mouth and connected directly to a desktop computer. Speech samples were recorded using the GoldWave program (Version 5.12, GoldWave, Inc., 2005), with a sampling rate set at $48 \mathrm{kHz}$ (16 bit), mono channel (see Rochman and Amir, 2013 for a brief introductory tutorial on basic procedures for recording speech/voice and acquiring relevant acoustic measures).

\section{MANIPULATION}

Participants were told that they will play an internet game "Cyberball" (see Williams et al., 2000), and were asked to visualize the game in order to practice visual metallization skills. 
On the computer screen, participants were presented with their own picture, as well as two other "participants" pictures (one man and one woman). When receiving the ball from one of the other two players, participants were required to indicate to whom they would like to throw the ball, by clicking on the appropriate player picture. In all conditions, the game lasted 30 ball tosses (approximately $5 \mathrm{~min}$ ).

As already mentioned, there were three experimental conditions: Exclusion, Acceptance, and Popularity. In the Exclusion condition, the participant received three tosses $(10 \%)$ in the beginning of the game. The rest of the time the tosses were interchanged between the two other presumed players while the participant was being ignored. In the Acceptance condition, the ball was passed equally frequently to all participants, resulting in the participant receiving 10 tosses (33\%). In the Popularity condition the participant received 15 tosses (50\%).

\section{SELF-REPORT MEASURES}

\section{Basic needs threat questionnaire}

(Zadro et al., 2006), contains 12 items assessing the effect of the game: belonging (e.g., "I felt like an outsider during the Cyberball game"), control (e.g., "I felt that I was able to throw the ball as often as I wanted during the game"), self-esteem (e.g., "I felt somewhat inadequate during the Cyberball game"), and meaningful existence (e.g., "I felt nonexistent during the Cyberball game"). All items are rated on a 5-point scale.

Consistent with previous research, the internal consistency of the need scale as a whole was very high $(\alpha=0.93)$ (see Williams et al., 2000; Zadro et al., 2006). Additionally, the sub-scales of belongingness, control, self-esteem, and meaningful existence also exhibited adequate-to-high internal consistencies (alphas were $0.65 ; 0.85 ; 0.85 ; 0.77$ respectively).

The questionnaire also contained two additional items regarding the "task" (e.g., "What percent of the throws were thrown to you?" "To what extent were you included by the other participants during the game?"), and two 9-point bipolar scales assessing current mood ("negative/positive") and feelings of rejection during the game ("accepted/rejected").

\section{Liebowitz SA Scale-Self-Report}

(LSAS-SR; Fresco et al., 2001), a 24-item self-report questionnaire measuring anxiety and avoidance in social or performance situations on a $0-3$ scale. The LSAS-SR has been shown to have high internal consistency, strong convergent and discriminate validity, and high test-retest reliability (Baker et al., 2002; Fresco et al., 2001). In the present study, a Cronbach's $\alpha$ of 0.93 was obtained for the anxiety subscale and 0.90 for the avoidance subscale.

\section{Beck Depression Inventory}

(BDI; Beck et al., 1996), a 21-item, multiple-choice, self-report questionnaire that assesses affective, cognitive, motivational and somatic symptoms of depression. In the present study we obtained a Cronbach's $\alpha$ of 0.81 for this measure.

\section{ACOUSTIC MEASURES}

Mean Fundamental Frequency ( $m F 0$ ) represents the rate of vibration of the vocal folds during phonation and speech. It is measured in $\mathrm{Hz}$, and it is subjectively perceived as pitch. Men and women differ widely in mF0s, which is estimated to average around $220 \mathrm{~Hz}$ for women and $130 \mathrm{~Hz}$ for men in general (Peterson and Barney, 1952), as well as among Hebrew speakers (Most et al., 2000).

Vocal intensity reflects the amount of acoustic/vocal energy produced by the speaker and could be related to the effort used by the speaker to produce speech (Laukka et al., 2008). It is measured in decibels $(\mathrm{dB})$, and it is subjectively perceived as loudness.

\section{RESULTS}

\section{PARTICIPANTS' CHARACTERISTICS}

Table 1 presents means and standard deviations (in parentheses) of participants' characteristics. Participants $(n=104,58$ women) ranged in age from 17 to 35 , with a mean age of 23.41 years $(S D=3.13)$. Participants' level of education ranged from 12 to 18 years, with a mean of $13.17(S D=1.54)$. Participants LSAS scores ranged from 0 to 123 with a mean

Table 1 | Means and standard deviation (in parentheses) of participants' characteristics in the exclusion, acceptance, and popularity conditions according to social anxiety (SA) group.

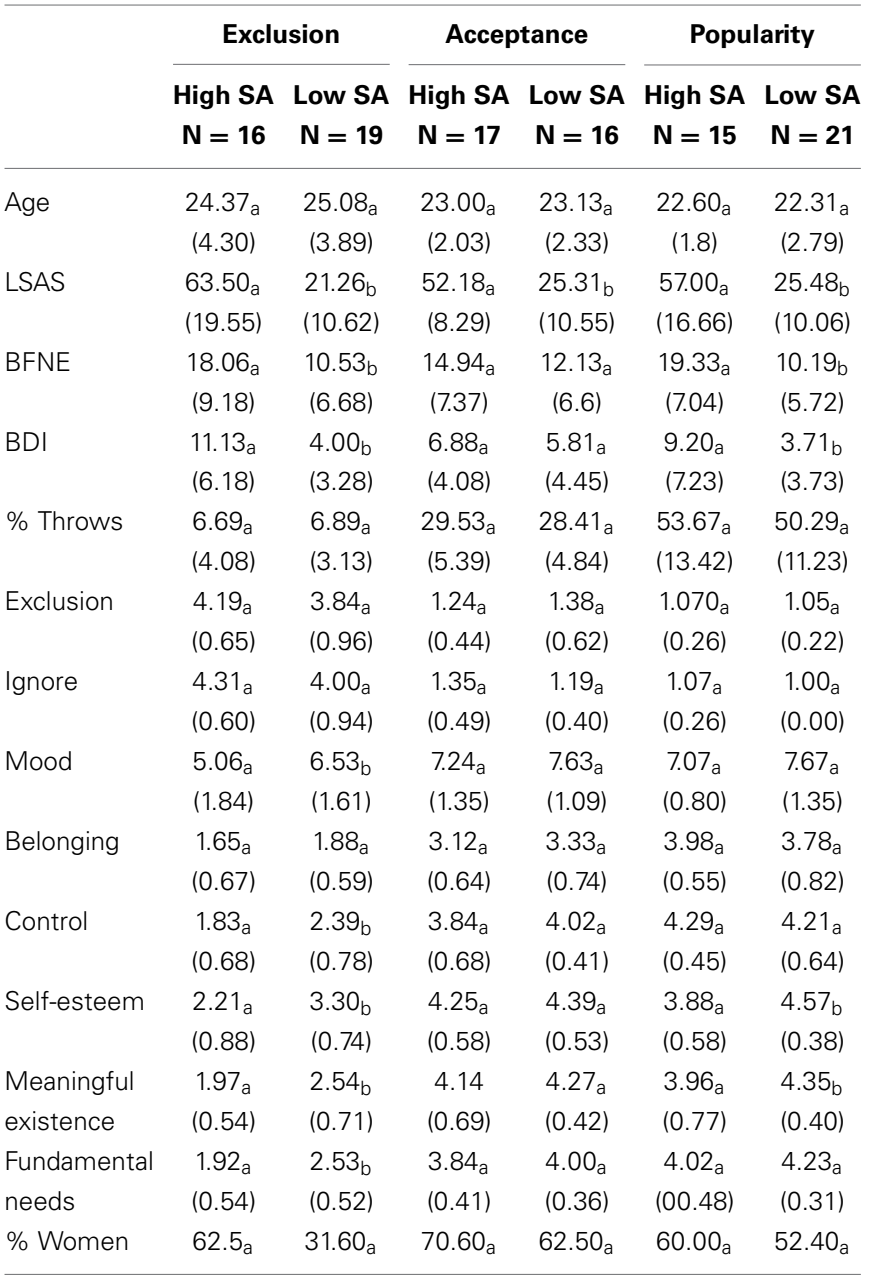

Different subscripts (i.e., a, b) within each pair represent differences at 0.05 level, and identical subscripts(a, a) represent a lack of statistically significant difference. 
score of $39.44(S D=21.28)$, and BDI scores ranged from 0 to 28 with a mean score of $6.54(S D=5.47)$. Participants were divided to high vs. low SA groups (HSA and LSA respectively) based on median split of LSAS at the time of the experiment. The mean LSAS score in the LSA group was $24(S D=$ $10.39)$ and the mean LSAS score in the HSA group was 57.46 $(S D=15.83)$.

\section{MANIPULATION CHECKS}

In order to assess whether participants correctly perceived the number of throws they received, we conducted a ThreeWay ANOVA with 3 (Condition: Exclusion, Acceptance, Popularity) $\times 2$ (Group: HSA, LSA) $\times 2$ (Gender: Men, Women) The analysis revealed the expected main effect of Condition, $\left[F_{(2,91)}=250.32, p<0.001, \eta^{2}=0.85\right]$. No other main effects or interactions were found (all $p s>0.36$ ). Thus, it is concluded that participants correctly perceived whether they were excluded, accepted, or made popular in the game. Moreover, SA group did not affect the correct estimation of perceived tosses $\left[F_{(1,91)}=0.62, p=0.43\right]$.

In order to assess whether participants correctly labeled their experiences, we conducted a Three-Way MANOVA on exclusion, ignoring, and acceptance ratings, with 3 (Condition: Exclusion, Acceptance, Popularity) $\times 2$ (Group: HSA, LSA) $\times 2$ (Gender: Men, Women) as between-subject variables. The analysis revealed the expected main effect of Condition, [Wilks' Lambda $F_{(6,178)}=$ 59.53, $\left.p<0.001, \eta^{2}=0.67\right]$. No other main effects or interactions were found (all $p s>0.93$ ).

\section{SUBJECTIVE SELF-REPORT}

In the examination of the exclusion reactivity hypothesis and the impaired positivity hypothesis we included BDI as a covariate, as it was significantly related to measures of interest $(r>-0.19$, $p=0.05)$. Participant's subjective self-report measures according to Condition, SA group and Gender are presented in Figure 1.

\section{The enhanced exclusion reactivity hypothesis}

To test this hypothesis we first conducted an ANCOVA on mood ratings with 2 (Condition: Exclusion, Acceptance) $\times 2$ (Group: HSA, LSA) $\times 2$ (Gender: Men, Women) as between-subject variables, and BDI as a covariate. A main effect of Condition was found, such that participants in the Exclusion condition reported lower mood as compared to the participants in the Acceptance condition $\left[F_{(1,59)}=14.78, p<0.001, \eta^{2}=0.20\right]$. A main effect of Group was found, such that individuals in the HSA group reported lower mood than did individuals in the LSA group $\left[F_{(1,59)}=5.69, p<0.02, \eta^{2}=0.08\right]$. The effect for Gender approached significance, such that women reported lower mood than did men $\left[F_{(1,59)}=3.39, p=0.07, \eta^{2}=0.05\right]$. Inconsistent with our hypothesis, no Group $\times$ Condition interaction was found $\left[F_{(1,59)}=1.18, p=0.28\right]$. No other main effects or interactions approached significance (all $p s>0.28$ ).

Next, we conducted a MANCOVA on fundamental needs scales (i.e., belongingness, control, self-esteem, and life meaning), with 2 (Condition: Exclusion, Acceptance) $\times 2$ (Group: HSA, LSA) $\times 2$ (Gender: Men, Women) as between-subject variables, and BDI as a covariate. A main effect of Condition was found, such that participants in the Exclusion condition reported having lower needs scores (i.e., more need-threat) than did participants in the Acceptance condition $\left[F_{(4,56)}=47.84, p<0.001\right.$, $\left.\eta^{2}=0.77\right]$. Moreover, the effect of Group approached significance, $\left[F_{(4,56)}=2.32, p=0.068, \eta^{2}=0.14\right]$, such that individuals with HSA tended to have lower needs scores than individuals with LSA. Finally, a Condition $\times$ Gender interaction was found, such that the difference in needs scores following Exclusion vs. Acceptance in women was greater than this difference among men $\left[F_{(4,56)}=2.88, p<0.03, \eta^{2}=0.17\right]$. In addition, consistent with our prediction, we found that, as compared to individuals with LSA, individuals with HSA reported lower self-esteem scores following Exclusion, as compared to the Acceptance conditions $\left[F_{(1,59)}=4.84, p<0.03, \eta^{2}=0.09\right]$. No other main effects or interactions approached significance (all $p s>0.27)$.
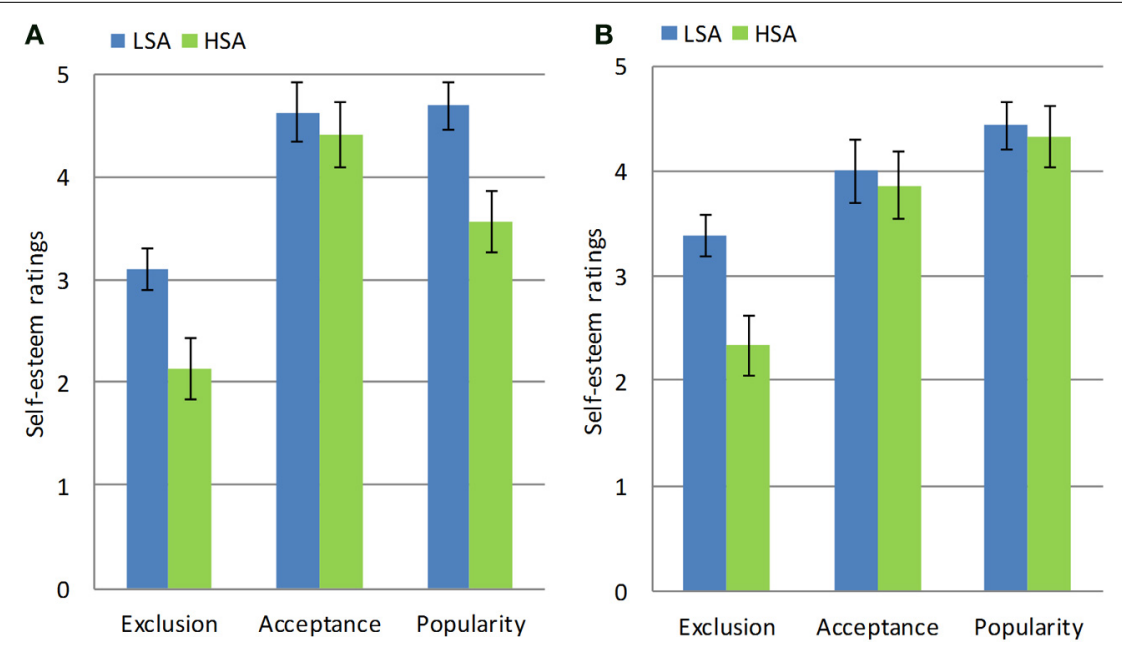

FIGURE 1 | Self-esteem measures of women (A) and men (B) in the high and low social anxiety groups following exclusion, acceptance, and popularity manipulations. Error bars represent standard errors of the mean. 


\section{The impaired positivity hypothesis}

In order to examine this hypothesis, we first conducted an ANCOVA on mood ratings, with 2 (Condition: Popularity, Acceptance) $\times 2$ (Group: HSA, LSA) × 2 (Gender: Men, Women) as between-subject variables, and BDI as a covariate. No main effect of Condition was found $\left[F_{(1,60)}=0.3, p=\right.$ 0.59]. A main effect of BDI was found, such that higher depression was associated with lower $\operatorname{mood}\left[F_{(1,60)}=4.02, p<0.05\right.$, $\left.\eta^{2}=0.06\right]$. A Condition $\times$ Gender interaction approached significance $\left[F_{(1,60)}=3.86, p=0.054, \eta^{2}=0.06\right]$. Importantly, this Two-Way interaction was modified by a three way interaction between Condition, Gender and Group $\left[F_{(1,60)}=5.69\right.$, $\left.p<0.02, \eta^{2}=0.08\right]$. We examined the differences for men and women separately. Men with HSA tended to report higher mood ratings following Popularity compared to Acceptance. At the same time, men with LSA did not evidence any difference in mood between the conditions $\left[F_{(1,22)}=2.36, p=0.14\right]$. In contrast, women with HSA tended to report lower mood ratings following Popularity as compared to Acceptance while LSA women did not evidence any difference in mood between the conditions $\left[F_{(1,37)}=2.85, p=0.1\right]$. In other words, the impaired positivity hypothesis was supported for women only, while men with HSA appeared to exhibit enhanced affective reactivity to Popularity. No other main effects or interactions were significant (all $p s>0.23$ ).

Next, we conducted a MANCOVA on fundamental needs scales, with 2 (Condition: Popularity, Acceptance) $\times 2$ (Group: HSA, LSA) $\times 2$ (Gender: Men, Women) as between-subject variables, and BDI as a covariate. A main effect of Condition was found, such that participants in the Popularity condition reported having higher needs scores (i.e., less need-threat) than did participants in the Acceptance condition $\left[F_{(4,57)}=4.57, p<0.003\right.$, $\left.\eta^{2}=0.24\right]$. Moreover, a significant effect of Group was found, such that individuals with HSA tended to have lower needs scores than individuals with $\operatorname{LSA}\left[F_{(4,57)}=2.66, p<0.04, \eta^{2}=0.16\right]$. Finally, a Condition $\times$ Gender interaction was found, such that the differences in needs scores for women in the Popularity vs. Acceptance condition were smaller than they were for men $\left[F_{(4,57)}=3.38, p<0.01, \eta^{2}=0.19\right]$.

An examination of the effects of the Self-esteem needs did not identify the predicted Group $\times$ Condition interaction $\left[F_{(1,60)}=2.78, p=0.1\right]$. However, a Three-Way Group $\times$ Condition $\times$ Gender interaction was found $\left[F_{(1,60)}=4.54\right.$, $\left.p<0.04, \eta^{2}=0.07\right]$. We examined the differences for men and women separately. Men with both high and low SA level tended to report higher self-esteem ratings following Popularity as compared to Acceptance $\left[F_{(4,19)}=2.59, p=0.07\right]$. Women in the HSA group reported lower self-esteem rating following Popularity as compared to Acceptance, while women in the LSA group did not evidence any difference in self-esteem between the conditions $\left[F_{(4,34)}=5.53, p<0.002, \eta^{2}=0.41\right]$. Again, the impaired positivity hypothesis was supported for women, but not for men. No other main effects or interactions were significant (all ps $>0.23$ ).

\section{ACOUSTIC MEASURES}

Acoustic analyses were performed using Praat@software (Version 4.1.2, Boersma and Weenink, 2009). Two parameters were extracted (a) mF0: mean fundamental frequency; and (b) Vocal intensity: mean speech vocal intensity. Only command and neutral utterances were analyzed, as we did not generate specific predictions for the request utterances. In light of our hypotheses, we focused on the main effect and interactions involving Group.

For each acoustic parameter, outliers of more than three standard deviations above or below the mean were excluded from the analysis (as in Weeks et al., 2011). Means and standard deviation for each parameter in each Sentence-type and Gender are presented in Table 2. Because there was no correlation between BDI and $\mathrm{mF} 0$ or vocal intensity, BDI was not included in the analyses.

\section{Vocal insecurity following exclusion hypothesis}

In order to test this hypothesis, we conducted two separate repeated measures analyses on $\mathrm{mF} 0$ and vocal intensity. To this end, a difference score between the pre- and post-manipulation measurement was computed for each participant in the Exclusion condition for $\mathrm{mF} 0$ and vocal intensity of command and neutral utterances. Changes in acoustic parameters following Exclusion according to SA group and Gender are presented in Figures 2, 3.

First, an ANOVA on mF0 was conducted with Gender (Men, Women) and Group (LSA, HSA) as between-subject variables, and Sentence-type (Neutral, Command) as a within-subject variable. A significant main effect of Group was found, such that overall, individuals with LSA exhibited a decrease in $\mathrm{mF0}$ compared to individuals with HSA, for whom mF0 increased $\left[F_{(1,31)}=\right.$ 13.26, $p<0.001, \eta^{2}=0.30$ ]. Importantly, and consistent with our hypothesis, this main effect was modified by a significant Sentence-type $\times$ Group interaction, such that only individuals with LSA lowered their $\mathrm{mF} 0$ from neutral to command sentences $\left[F_{(1,31)}=17.33, p<0.001, \eta^{2}=0.36\right]$. Because of the significant differences in $\mathrm{mF0}$ between men and women, we examined these findings separately for each gender. Results confirmed that this interaction was significant for both men $\left[F_{(1,17)}=13.23\right.$, $\left.p<0.002, \eta^{2}=0.44\right]$ and women $\left[F_{(1,14)}=5.95, p<0.03\right.$, $\left.\eta^{2}=0.30\right]$.

Then, a similar ANOVA was conducted for the vocal intensity measure. A significant Three-Way Sentence-type $\times$ Gender $\times$ Group interaction was found $\left[F_{(1,30)}=6.93, p<0.001, \eta^{2}=\right.$ $0.19]$. Consistent with our hypothesis, LSA men increased their vocal intensity, while HSA men decreased their vocal intensity in command utterances, as compared to neutral sentences $\left[F_{(1,16)}=7.26, p<0.02, \eta^{2}=0.31\right]$. In contrast, both HSA and LSA women exhibited a greater increase in vocal intensity for command sentences as compared to neutral sentences $\left[F_{(1,14)}=\right.$ 4.6, $\left.p<0.05, \eta^{2}=0.25\right]$.

\section{Vocal confidence following popularity hypothesis}

In order to test this hypothesis, we conducted two separate repeated measures analyses on $\mathrm{mF} 0$ and vocal intensity. Similarly to the Exclusion condition, we used the difference score between the pre- and post-Popularity measures in acoustic parameters (mF0, vocal intensity) for command and neutral utterances.

An ANOVA on mF0 was conducted with Gender (Men, Women) and Group (LSA, HSA) as between-subject variables, and Sentence-type (Neutral, Command) as a within-subject 
Table 2 | Means and standard deviation (in parentheses) of acoustic parameters recorded after exclusion and popularity conditions according to social anxiety (SA) group and gender.

\begin{tabular}{|c|c|c|c|c|c|c|}
\hline & \multicolumn{3}{|c|}{ Low SA } & \multicolumn{3}{|c|}{ High SA } \\
\hline Neutral sentences & & & & & & \\
\hline $\mathrm{mF0}(\mathrm{M})$ & $123.23(5.42)$ & $122.12(5.3)$ & $-0.53(2.01)$ & 143.86 (7.98) & 146.77 (7.79) & $1.83(2.99)$ \\
\hline $\mathrm{mF0}(\mathrm{W})$ & 192.33 (7.98) & 191.06 (7.79) & $-1.27(2.73)$ & $208.69(6.18)$ & $209.89(6.04)$ & $0.08(2.23)$ \\
\hline \multicolumn{7}{|l|}{ Command sentences } \\
\hline mF0 (M) & $150.4(6.78)$ & $140.25(6.77)$ & $-9.57(3.37)$ & 162.42 (9.99) & 168.89 (9.96) & $7.83(5.00)$ \\
\hline mF0 (W) & 228.76 (9.99) & $214.5(9.96)$ & $-14.26(4.56)$ & $234.61(7.74)$ & $235.12(7.72)$ & $-1.22(3.73)$ \\
\hline Vocal intensity (M) & $76.89(1.42)$ & $72.92(1.22)$ & $4.03(1.27)$ & $71.1(2.09)$ & $75.74(1.79)$ & $-4.89(1.89)$ \\
\hline mFo (W) & $207.89(8.8)$ & $204.15(8.71)$ & $-3.74(4.32)$ & $220.6(6.82)$ & $212.06(6.75)$ & $-7.44(3.53)$ \\
\hline Vocal intensity (M) & $70.24(1.38)$ & $69.38(1.2)$ & $-1.34(1.50)$ & $66.4(2.036)$ & 72.34 (1.769) & $7.38(2.23)$ \\
\hline Vocal intensity (W) & $70.15(2.04)$ & $71.06(1.77)$ & $0.91(2.04)$ & $67.37(1.58)$ & $66.51(1.47)$ & $-0.97(1.66)$ \\
\hline \multicolumn{7}{|c|}{ POPULARITY CONDITION } \\
\hline \multicolumn{7}{|c|}{ Neutral sentences } \\
\hline $\mathrm{mF0}(\mathrm{M})$ & $114.18(6.18)$ & $115.74(6.04)$ & $1.16(2.36)$ & $121.8(7.979)$ & $124.38(7.79)$ & $1.32(2.99)$ \\
\hline $\mathrm{mF0}(\mathrm{W})$ & $196.58(5.89)$ & $198.16(5.76)$ & $1.58(2.01)$ & $194.24(6.91)$ & $198.78(6.75)$ & $4.54(2.36)$ \\
\hline Vocal intensity (M) & $69.32(1.46)$ & $71.1(1.31)$ & $-0.23(1.96)$ & $70.52(1.89)$ & $69.5(1.69)$ & $3.02(2.448)$ \\
\hline Vocal intensity (W) & $68.76(1.4)$ & $69.19(1.24)$ & $0.43(1.68)$ & $69.72(1.54)$ & $69.68(1.38)$ & $0.41(1.96)$ \\
\hline \multicolumn{7}{|l|}{ Command sentences } \\
\hline \multicolumn{7}{|l|}{ Request sentences } \\
\hline mFo (W) & $202.36(6.5)$ & $202.89(6.43)$ & $0.54(3.19)$ & $207.24(7.62)$ & $210.59(7.54)$ & $3.34(3.74)$ \\
\hline Vocal intensity (M) & $68.01(1.58)$ & $67.18(1.37)$ & $-2.34(1.76)$ & $68.12(2.04)$ & $69.31(1.77)$ & $1.27(2.23)$ \\
\hline Vocal intensity (W) & $68.43(1.5)$ & $67.76(1.31)$ & $-0.67(1.50)$ & $69.08(1.66)$ & $68.59(1.44)$ & $-0.26(1.76)$ \\
\hline
\end{tabular}

variable. No significant effects or interactions were identified (all ps $>0.13$ ). A similar ANOVA was conducted on the vocal intensity measures, with no significant main effects or interactions (all ps $>0.25$ ).

\section{DISCUSSION}

The present study examined reactivity to changes in belongingness based on subjective and expressive (implicit) measures in individuals high and low on a self-report measure of SA. First, our exclusion-reactivity hypothesis was partially supported. Our results support previous findings that threat to belongingness has a general negative effect on individuals, but that, on most measures, the immediate effect of exclusion is not associated with individual differences (Zadro et al., 2006; Oaten et al.,
2008; Williams, 2009; but see also Wesselmann et al., 2012a,b). Specifically, we did not find that individuals with HSA reported lower mood or higher threat of their fundamental needs following exclusion (as compared to acceptance), as compared to individuals with LSA. However, consistent with our hypothesis, we found that, as compared to individuals with LSA, individuals with HSA were more affected by exclusion (than acceptance) condition on measures assessing self-esteem. Importantly, these findings held while controlling for significant effects of depressive symptoms severity. Thus, while there were no differences in the way that HSA and LSA individuals perceived the reality of the interaction (i.e., both groups estimated number of throws equally accurately), HSA individuals reported lower self-esteem following exclusion than following acceptance than did LSA individuals. These results 

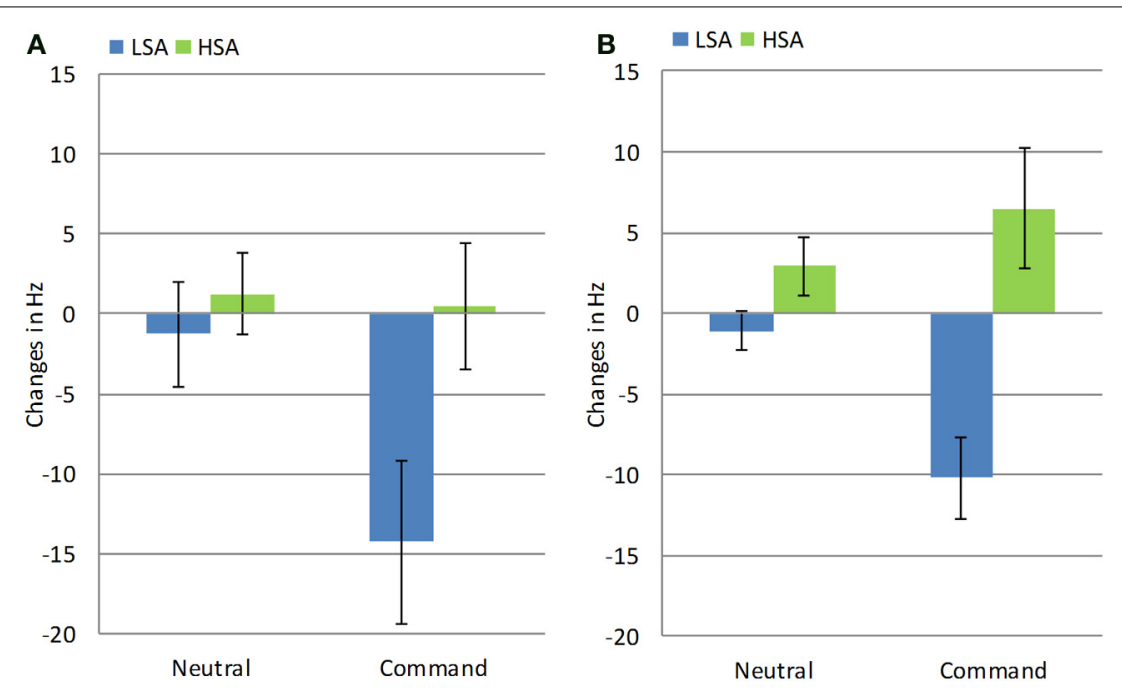

FIGURE 2 | Changes in mF0 following exclusion in high and low socially anxious women (A) and men (B). Error bars represent standard errors of the mean.
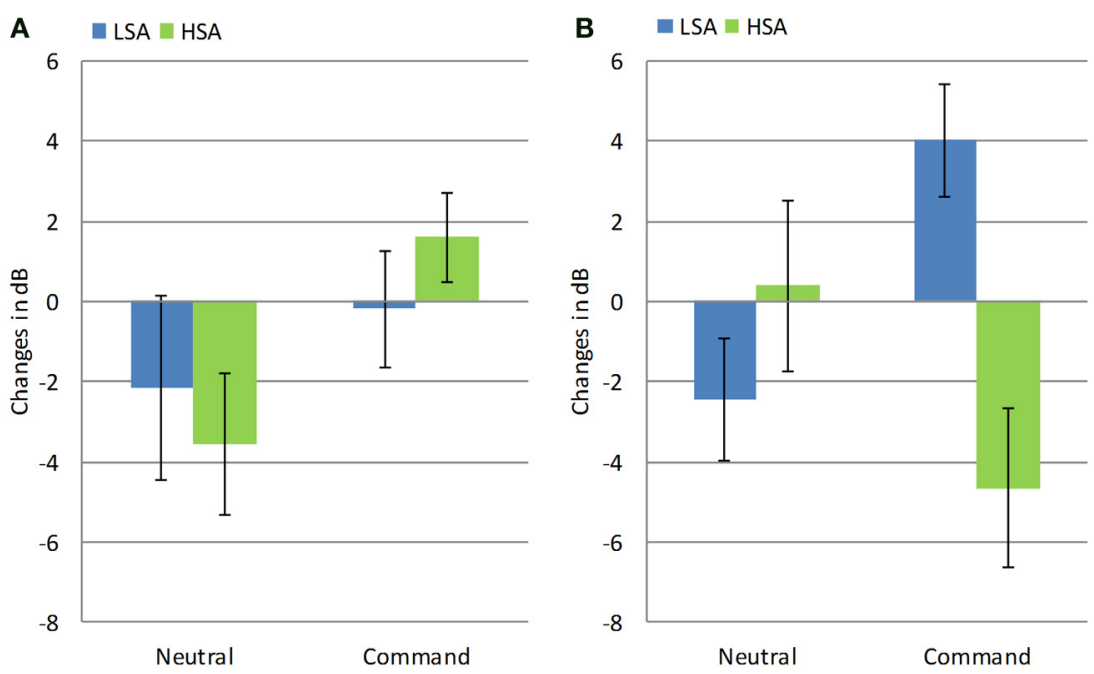

FIGURE 3 | Changes in vocal intensity following exclusion in high and low socially anxious women (A) and men (B). Error bars represent standard errors of the mean.

are consistent with previous findings demonstrating that SA in children was associated with greater changes in self-esteem following rejection (Reijntjes et al., 2011). Thus, the present findings are broadly consistent with Leary's view of SA as possessing an over-sensitive sociometers (e.g., Leary and Jongman-Sereno, in press).

Second, we tested the impaired positivity hypothesis, which postulated that individuals with HSA will report attenuated subjective reactions to popularity compared to acceptance. Our impaired positivity hypothesis was supported for women, but not for men. Specifically, we found that while SA did not affect men's self-esteem ratings in response to popularity as opposed to acceptance, HSA, but not LSA women, reported decreases in mood and in self-esteem. Importantly, men with HSA were found to be more affectively responsive to popularity than to acceptance as opposed to men with LSA. It appears that HSA men are more dependent on external feedback than are LSA men. These findings support and extend the research showing that gender exerts a significant effect on interpersonal relationships (e.g., Benenson, 1990; Kwang et al., 2013). Specifically, it is possible that while social visibility (being at the center) does not carry negative costs for men, such visibility may incur negative consequences for women (e.g., Cillessen and Borch, 2006). Alternatively, it is also possible that popularity in the ball-tossing game carries different (and more positive) connotations for men than for women.

Third, we postulated that individuals with HSA would exhibit a pattern of vocal insecurity following exclusion, whereas individuals with LSA would not exhibit this pattern. This hypothesis was 
mostly supported by our findings. Specifically, we found that HSA men exhibited an increase in $\mathrm{mF} 0$ and a decrease in vocal intensity in command sentences. In contrast, LSA men exhibited an opposite pattern: they evidenced a decrease in $\mathrm{mF} 0$ and an increase in vocal intensity. Similarly, HSA women uttered command sentences in higher mF0 than did LSA women. Taken together, these findings suggest that after experiencing exclusion, men, and to a somewhat lesser extent, women, with LSA exhibit a confident and dominant pattern of responses, while individuals with HSA exhibit an insecure pattern.

Fourth, we tested the impaired confidence hypotheses, according to which HSA individuals are expected to exhibit a less pronounced increase in vocal confidence than those with LSA after experiencing a popularity condition. This hypothesis was not supported by our data.

\section{SOCIAL EXCLUSION: REPARATIVE REPERTOIRE}

When interpersonal status-quo is threatened, due to social exclusion or rejection, the need to take reparative action arises. Such a need is likely to mobilize various subsystems, energize behavior, attune the sensitivity of the cognitive system to signals of acceptance or rejection, and influence motivation and behavior. Previous studies have documented that social exclusion may lead to distinct types of responses. These include social coldness/avoidance (e.g., DeWall and Baumeister, 2006; Twenge et al., 2007), affiliation (Maner et al., 2007; Dewall et al., 2009) and aggression (Twenge et al., 2001; DeWall et al., 2010). Insofar as acoustic parameters are seen as proxy for interpersonal strategies, our study suggests that, some individuals react to social exclusion by adopting strategies aimed for restoring social status, while others may react by "profile lowering" and utilization of behaviors typically associated with submissiveness and deference.

The interpersonal circumplex (e.g., Wiggins, 1979) conceptualizes the realm of social behaviors as consisting of two axes: dominance (i.e., power, competence, agency) and affiliation (i.e., warmth, love, communion). When examined through this prism, social exclusion can either heighten or lower the desire to affiliate, and the motivation to restore social rank. This conceptualization brings the rather disparate literature of reactions to exclusion under a unified theoretical umbrella, suggesting that exclusion (and possibly popularity) may lead to the use of strategies for increasing social rank, and not only those intended to regain social acceptance. In addition, social exclusion may lead to the simultaneous employment of several types of coping strategies, as people may increase their social visibility while also increasing the affiliative efforts on the one hand, or signal deference and social withdrawal on the other hand (see also Powers and Heatherton, 2012). Considered in concert, these findings are suggestive of the great flexibility and diversity of responses to social exclusion.

\section{EXCLUSION AND SOCIAL ANXIETY}

In this study we found that vocal characteristics of command and neutral sentences provided cues for changes in belongingness status, and that individual differences (gender, SA) modulated these effects. Specifically, we suggest that HSA individuals respond to social exclusion by using submissive tactics. These findings are in line with previous studies, which similarly found that individuals with HSA report using more submissive behaviors and endorse more submissive cognitions than individuals with LSA (Aderka et al., 2009; Weeks et al., 2011). In addition, other studies have found that individuals high in SA were rated as less dominant, and that HSA women made greater efforts to minimize interpersonal disharmony than did LSA women, by using more appeasement statements (Oakman et al., 2003).

These findings lent further support to theoretical accounts which place concerns with social rank and power at the core of SA (e.g., Gilbert, 2001; Gilbert and Trower, 2001; Mineka and Öhman, 2002; Johnson et al., 2012; Gilboa-Schechtman and Shachar-Lavie, 2013). HSA individuals opt for submissive or deferring responses when faced with social threats-either exclusion or defeat. Future studies may explore whether, and under what conditions, social exclusion/rejection in HSA individuals leads to deficits in affiliative behavior, deficits in assertive behaviors, or general social withdrawal.

Recent studies focused on the neural correlates of interpersonal exclusion in individuals with psychopathology (e.g., Maurage et al., 2012). Specifically, Maurage and colleagues found that, as compared to controls, individuals with alcohol dependence, exhibited increased activation in brain "reactivity" areas (i.e., areas usually associated with social exclusion feelings such as dorsal anterior cingulate cortex, insula) as well as decreased activation in areas associated with regulations of those feelings (e.g., middle frontal gyrus and inferior frontal gyrus). Extending these studies to examine the neural correlates of social exclusion (and possibly social rank loss) in SA may strengthen our understanding of core mechanism(s) of this disorder.

The present findings extend existing research in several ways. First, while previous research focused mostly on affiliative responses following exclusion (e.g., Maner et al., 2007; Mallott et al., 2009; Buckner et al., 2010; Tai et al., 2011), we focused on responses connoting dominance and submissiveness. Second, we examined expressive interpersonal responses. The emphasis on production, rather than perception of social signals, is essential for evaluating the impact of behaviors of socially anxious individuals on their chances of creating a supportive and respectful interaction. In addition to conveying the speaker's emotional states, vocal expressions may also serve as a signal to the listener, serving as an appeal for reaction (Laukka and Elfenbein, 2011). Such expressions modulate and coordinate interpersonal interactions. Third, we found that the pattern of affective, cognitive, and behavioral response was specific to SA, rather than emerging from concomitant depressive symptoms. This emphasizes the impaired reactions to exclusion as a core feature of SA.

\section{POPULARITY, SOCIAL ANXIETY, AND GENDER}

Evolutionary and interpersonal perspectives converge in suggesting that social stress arises in response to changes and modulation in social standing and social fortunes (e.g., Gilbert and Trower, 2001; Alden and Taylor, 2004). While research so far has focused on the examination of social threats (e.g., public speaking) and negative social events (e.g., exclusion, rejection), we examined the after-effects of exclusive social attention (popularity). Consistent with impaired positivity accounts, our findings suggest that the effects of enhanced social attention tend to be 
negative for women high (but not low) in SA. The mood and selfesteem of women with HSA decreased in situations of enhanced attention, compared to situations of equal attention (see also Gilboa-Schechtman et al., 2000; Gilbert and Trower, 2001; Alden et al., 2008; Weeks, 2010; Gilboa-Schechtman et al., 2013a,b). In contrast, men did not exhibit the predicted negatively biased reactivity to popularity. Instead, in that condition, men tended to exhibit an enhanced affective reactivity, supporting a high contingency of social esteem and external approval on SA (Reijntjes et al., 2011; Leary and Jongman-Sereno, in press). It is possible that, while no differences in subjective experience following exclusive social attention are reported by men high and low in SA, brain activation measures may unveil a different, more sensitive, pattern (for a similar argument, see Eisenberger and Lieberman, 2004).

\section{LIMITATIONS AND FUTURE DIRECTIONS}

Several limitations of our study should be noted. First, while the popularity condition affected the perceptions and the fundamental needs of our participants, it did not affect their mood ratings or the acoustic measures. We take these findings to mean that our popularity manipulation is a less powerful counterpart to the exclusion condition. Future research may attempt to enhance the effectiveness of popularity manipulation by using alternative procedures. Such alternatives could include the "survivor game" used by Reijntjes et al. (2011), the interpersonal rejection paradigm, as in Mallott et al. (2009), or a modification of the Cyberball procedure that would include additional participants, to enhance the difference between the acceptance and the popularity conditions. Second, we used only post-manipulation measures of mood, as typically performed in previous studies with Cyberball. Thus, we could only compare both exclusion and popularity conditions to the acceptance condition. Such comparisons are clearly less sensitive than within-subject comparisons. Future studies may use other manipulations allowing the assessment of pre- and post-mood measures. Third, our findings need to be replicated with spontaneous, rather than planned speech. Spontaneous speech is likely to involve increased task demands, as the speaker is concerned with the content of communication as well as with its manner. This may lead to greater or more pervasive disruption in vocal characteristics. Fourth, in this study we focused on a limited number of acoustic parameters. A more comprehensive examination of a wide range of expressive tactics (vocal, postural, facial) would enrich our understanding of the ways in which humans express intentions and emotions. Fifth, our sample size was rather small, likely restricting our ability to detect some individual differences. Sixth, our results need to be replicated in a clinical population. While there is considerable evidence that SA and SAD form a continuum (e.g., Ruscio, 2010; Haslam et al., 2012), it is possible that individuals with clinical levels of SA exhibit qualitatively different forms of impairment. Moreover, future studies could profit from a differentiation between the effects of social and generalized anxiety on responses to changes in belongingness. Finally, in our study we examined the effects of threats to belongingness. An extension of the present finding to other domains, such as threats to social status (e.g., winning or losing a competition), would allow a greater understanding of the response to changes in interpersonal fortunes in SA.

\section{SUMMARY AND CONCLUSIONS}

Despite these limitations, we believe that our study makes several contributions. First, we show that a brief manipulation of exclusion exerts significant and differential effects on vocal expression, which can be quantified objectively. Indeed, our study is the first to suggest that social exclusion affects expressive interpersonal signals. Second, we argue that vocal changes exhibited by highly socially anxious individuals (especially males) are related to dominance expression impairment. Taken together with previous research on vocal properties of speech in socially anxious individuals (e.g., Weeks et al., 2012; Galili et al., 2013) our data suggest that vocal parameters of speech, especially $\mathrm{mF} 0$, may be used as objective markers of SA. Third, our data point to the hypersensitivity of social rank biobehavioral system functioning in SA (see also Johnson et al., 2012). In fact, reactivity to changes in social fortune may emerge as a core vulnerability in SA (see also Levinson et al., 2013). Indeed, such a conceptualization of SA may inform interventions which can be designed to decrease the reactivity and increase the adaptability of socially anxious individuals' response to changes in belongingness and in social rank. Fourth, significant differences in the subjective reactions of socially anxious men and women to changes in belongingness were found. These findings are consistent with evolutionary and interpersonal accounts of SA and highlight the importance of examining the effects of SA and gender on expressive and subjective reactions to events connoting social acceptance and ascendance. The examination of SA from the perspective of basic psychological systems may offer a new, theory-based approach to the nosology and treatment of this highly prevalent anxiety disorder.

\section{AUTHOR CONTRIBUTIONS}

Eva Gilboa-Schechtman was responsible for the design of the study, supervised the running of the participants, performed the majority of data analyses, and wrote the study for publication. Lior Galili assisted in the running of the study, analysis of the vocal data and write-up. Yair Sahar assisted in data analyses and write-up. Ofer Amir supervised the vocal analysis and assisted in write-up.

\section{ACKNOWLEDGMENTS}

This work was supported by the Israeli Science Foundation, 45510 awarded to Eva Gilboa-Schechtman. The authors would also like to thank Or Lam, Einav Horev, Hadar Keshet, and Iris Shahar for their help with the preparation of this work.

\section{REFERENCES}

Aderka, I. M., Hofmann, S. G., Nickerson, A., Hermesh, H., GilboaSchechtman, E., and Marom, S. (2012). Functional impairment in social anxiety disorder. J. Anxiety Disord. 26, 393-400. doi: 10.1016/j.janxdis.2012. 01.003

Aderka, I. M., Weisman, O., Shahar, G., and Gilboa-Schechtman, E. (2009). The roles of the social rank and attachment systems in social anxiety. Pers. Individ. Dif. 47, 284-288. doi: 10.1016/j.paid.2009.03.014 
Alden, L. E., Mellings, T. M. B., and Laposa, J. M. (2004). Framing social information and generalized social phobia. Behav. Res. Ther. 42, 585-600. doi: 10.1016/S0005-7967(03)00163-3

Alden, L. E., and Taylor, C. T. (2004). Interpersonal processes in social phobia. Clin. Psychol. Rev. 24, 857-882. doi: 10.1016/j.cpr.2004.07.006

Alden, L. E., Taylor, C. T., Mellings, T. M. J. B., and Laposa, J. M. (2008). Social anxiety and the interpretation of positive social events. J. Anxiety Disord. 22, 577-590. doi: 10.1016/j.janxdis.2007.05.007

Alden, L. E., and Wallace, T. (1995). Social phobia and social appraisal in successful and unsuccessful social interactions. Behav. Res. Ther. 33, 497-505. doi: 10.1016/0005-7967(94)00088-2

American Psychiatric Association. (2000). Diagnostic and Statistical Manual of Mental Disorders, 4th Edn, Text Revision. Washington, DC: American Psychiatric Association. doi: 10.1176/appi.books.9780890423349

Baer, L., and Blais, M. A. (2010). Handbook of Clinical Rating Scales and Assessment in Psychiatry and Mental Health In Current Clinical Psychiatry, Vol. 21. New York: Humana Press. doi: 10.1007/978-1-59745-387-5

Baker, S. L., Heinrichs, N., Kim, H. J., and Hofmann, S. G. (2002). The Liebowitz social anxiety scale as a self-report instrument: a preliminary psychometric analysis. Behav. Res. Ther. 40, 701-715. doi: 10.1016/S0005-7967(01) 00060-2

Baumeister, R. F., and Leary, M. R. (1995). The need to belong: desire for interpersonal attachments as a fundamental human motivation. Psychol. Bull. 117, 497-529. doi: 10.1037/0033-2909.117.3.497

Beck, A. T., Steer, R. A., and Brown, G. K. (1996). Manual for the Beck Depression Inventory-II. San Antonio, TX: Psychological Corporation.

Benenson, J. F. (1990). Gender differences in social networks. J. Early Adolesc. 10, 472-495. doi: 10.1177/0272431690104004

Bittner, A., Goodwin, R. D., Wittchen, H. U., Beesdo, K., Höfler, M., and Lieb, R. (2004). What characteristics of primary anxiety disorders predict subsequent major depressive disorder? J. Clin. Psychiatry 65, 618-626. doi: 10.4088/JCP.v65n0505

Blackhart, G. C., Eckel, L. A., and Tice, D. M. (2007). Salivary cortisol in response to acute social rejection and acceptance by peers. Biol. Psychol. 75, 267-276. doi: 10.1016/j.biopsycho.2007.03.005

Boehm, J. K., and Kubzansky, L. D. (2012). The heart's content: the association between positive psychological well-being and cardiovascular health. Psychol. Bull. 138, 655-691. doi: 10.1037/a0027448

Boersma, P., and Weenink, D. (2009). Praat: Doing Phonetics by Computer [Computer Program]. Version 5.1.05. Available online at: http://www.praat.org/

Buckner, J. D., Dewall, C. N., Schmidt, N. B., and Maner, J. K. (2010). A tale of two threats: social anxiety and attention to social threat as a function of social exclusion and non-exclusion threats. Cogn. Ther. Res. 34, 449-455. doi: 10.1007/s10608-009-9254-x

Bugental, D. B., Beaulieu, D. A., Schwartz, A., and Dragosits, R. (2009). Domainspecific responses to power-based interaction. J. Exp. Soc. Psychol. 45, 386-391. doi: 10.1016/j.jesp.2008.10.005

Cillessen, A. H. N., and Borch, C. (2006). Developmental trajectories of adolescent popularity: a growth curve modelling analysis. J. Adolesc. 29, 935-959. doi: 10.1016/j.adolescence.2006.05.005

Clark, D. M., and Wells, A. (1995). "A cognitive model of social phobia," in Social Phobia: Diagnosis, Assessment, and Treatment, eds R. G. Heimberg, M. R. Liebowitz, D. A. Hope, and F. R. Schneier (New York, NY: Guilford Press), 69-93.

Davidson, K. W., Mostofsky, E., and Whang, W. (2010). Don't worry, be happy: positive affect and reduced 10-year incident coronary heart disease: the Canadian Nova Scotia Health Survey. Eur. Heart J. 31, 1065-1070. doi: 10.1093/eurheartj/ehp603

DeWall, C. N., and Baumeister, R. F. (2006). Alone but feeling no pain: effects of social exclusion on physical pain tolerance and pain threshold, affective forecasting, and interpersonal empathy. J. Pers. Soc. Psychol. 91, 1-15. doi: 10.1037/0022-3514.91.1.1

DeWall, C. N., Deckman, T., Pond, R. S., and Bonser, I. (2011). Belongingness as a core personality trait: how social exclusion influences social functioning and personality expression. J. Pers. 79, 1281-1314. doi: 10.1111/j.14676494.2010.00695.x

Dewall, C. N., Maner, J. K., and Rouby, D. A. (2009). Social exclusion and earlystage interpersonal perception: selective attention to signs of acceptance. J. Pers. Soc. Psychol. 96, 729-741. doi: 10.1037/a0014634
DeWall, C. N., Twenge, J. M., Bushman, B., Im, C., and Williams, K. (2010). A little acceptance goes a long way: applying social impact theory to the rejection-aggression link. Soc. Psychol. Pers. Sci. 1, 168-174. doi: $10.1177 / 1948550610361387$

Diamond, G. M., Rochman, D., and Amir, O. (2010). Arousing primary vulnerable emotions in the context of unresolved anger: "Speaking about" vs. "speaking to." J. Couns. Psychol. 57, 402-410. doi: 10.1037/a0021115

Eisenberger, N. I., and Lieberman, M. D. (2004). Why rejection hurts: a common neural alarm system for physical and social pain. Trends Cogn. Sci. 8, 294-300. doi: 10.1016/j.tics.2004.05.010

Eisenberger, N. I., Lieberman, M. D., and Williams, K. D. (2003). Does rejection hurt? An fMRI study of social exclusion. Science 302, 290-292. doi: 10.1126/science.1089134

Elfenbein, H. A., and Ambady, N. (2002). On the universality and cultural specificity of emotion recognition: a meta-analysis. Psychol. Bull. 128, 203-235. doi: 10.1037/0033-2909.128.2.203

Fredrickson, B. L., Tugade, M. M., Waugh, C. E., and Larkin, G. R. (2003). What good are positive emotions in crisis? A prospective study of resilience and emotions following the terrorist attacks on the United States on September 11th, 2001. J. Pers. Soc. Psychol. 84, 365-376. doi: 10.1037/0022-3514. 84.2.365

Fresco, D. M., Coles, M. E., Heimberg, R. G., Liebowitz, M. R., Hami, S., Stein, M. B., et al. (2001). The Liebowitz Social Anxiety Scale: a comparison of the psychometric properties of self-report and clinician-administered formats. Psychol. Med. 31, 1025-1035. doi: 10.1017/S0033291701004056

Galili, L., Amir, O., and Gilboa-Schechtman, E. (2013). Acoustic properties of dominance and request utterances in social anxiety. J. Soc. Clin. Psychol. 32, 651-673. doi: 10.1521/jscp.2013.32.6.651

Gazelle, H., and Druhen, M. J. (2009). Anxious solitude and peer exclusion predict social helplessness, upset affect, and vagal regulation in response to behavioral rejection by a friend. Dev. Psychol. 45, 1077-1096. doi: 10.1037/a0016165

Gilbert, P. (2001). Evolution and social anxiety: the role of attraction, social competition, and social hierarchies. Psychiatr. Clin. North Am. 24, 723-751. doi: 10.1016/S0193-953X(05)70260-4

Gilbert, P., and Trower, P. (2001). Evolution and Process iSocial Anxiety. New York, NY, US: John Wiley and Sons Ltd. 259-279.

Gilboa-Schechtman, E., Franklin, M. E., and Foa, E. B. (2000). Anticipated reactions to social events: differences among individuals with generalized social phobia, obsessive compulsive disorder, and nonanxious controls. Cogn. Ther. Res. 24, 731-746. doi: 10.1023/A:1005595513315

Gilboa-Schechtman, E., Friedman, L., Helpman, L., and Kananov, J. (2013a). Selfevaluations of social rank and affiliation in social anxiety disorder: explicit and implicit measures. Int. J. Cogn. Ther. 6, 208-220. doi: 10.1521/ijct.2013.6.3.208

Gilboa-Schechtman, E., and Shachar-Lavie, I. (2013). More than a face: a unified theoretical perspective on nonverbal social cue processing in social anxiety. Front. Hum. Neurosci. 7:904. doi: 10.3389/fnhum.2013.00904

Gilboa-Schechtman, E., Shachar, I., and Sahar, Y. (2013b). "Positivity impairment as a broad-based feature of social anxiety," in Handbook of Social Anxiety Disorder, ed J. Weeks (New York, NY: Wiley-Blackwell Publishing Ltd).

Haslam, N., Holland, E., and Kuppens, P. (2012). Categories vs. dimensions in personality and psychopathology: a quantitative review of taxometric research. Psychol. Med. 42, 903-920. doi: 10.1017/S0033291711001966

Hess, Y. D., and Pickett, C. L. (2010). Social rejection and self- vs. other-awareness. J. Exp. Soc. Psychol. 46, 453-456. doi: 10.1016/j.jesp.2009.12.004

Hofmann, S. G., Heinrichs, N., and Moscovitch, D. A. (2004). The nature and expression of social phobia: toward a new classification. Clin. Psychol. Rev. 24, 769-797. doi: 10.1016/j.cpr.2004.07.004

Johnson, S. L., Leedom, L. J., and Muhtadie, L. (2012). The dominance behavioral system and psychopathology: evidence from self-report, observational, and biological studies. Psychol. Bull. 138, 692-743. doi: 10.1037/a0027503

Jones, B. C., Feinberg, D. R., DeBruine, L. M., Little, A. C., and Vukovic, J. (2010). A domain-specific opposite-sex bias in human preferences for manipulated voice pitch. Anim. Behav. 79, 57-62. doi: 10.1016/j.anbehav.2009.10.003

Juslin, P. N., and Laukka, P. (2004). Expression, perception, and induction of musical emotions: a review and a questionnaire study of everyday listening. J. New Music Res. 33, 217-238. doi: 10.1080/0929821042000317813

Kashdan, T. B. (2007). Social anxiety spectrum and diminished positive experiences: theoretical synthesis and meta-analysis. Clin. Psychol. Rev. 27, 348-365. doi: 10.1016/j.cpr.2006.12.003 
Kashdan, T. B., Weeks, J. W., and Savostyanova, A. A. (2011). Whether, how, and when social anxiety shapes positive experiences and events: a self-regulatory framework and treatment implications. Clin. Psychol. Rev. 31, 786-799. doi: 10.1016/j.cpr.2011.03.012

Kwang, T., Crockett, E. E., Sanchez, D. T., and Swann, W. B. (2013). Men seek social standing, women seek companionship: sex differences in deriving self-worth from relationships. Psychol. Sci. 24, 1142-1150. doi: 10.1177/0956797612467466

Lancaster, J. B. (1986). Primate social behavior and ostracism. Ethol. Sociobiol. 7, 215-225. doi: 10.1016/0162-3095(86)90049-X

Laukka, P., and Elfenbein, H. A. (2011). Emotion appraisal dimensions can be inferred from vocal expressions. Soc. Psychol. Pers. Sci. 3, 529-536. doi: $10.1177 / 1948550611428011$

Laukka, P., Linnman, C., Åhs, F., Pissiota, A., Frans, Ö., Faria, V., et al. (2008). In a nervous voice: acoustic analysis and perception of anxiety in social phobics' speech. J. Nonverbal Behav. 32, 195-214. doi: 10.1007/s10919-008-0055-9

Leary, M. R., Cottrell, C. A., and Phillips, M. (2001). Deconfounding the effects of dominance and social acceptance on self-esteem. J. Pers. Soc. Psychol. 81, 898-909. doi: 10.1037/0022-3514.81.5.898

Leary, M. R., and Jongman-Sereno, K. P. (in press). "Social anxiety as an early warning system: a refinement and extension of the self-presentation theory of social anxiety," in Social Anxiety: Clinical, Developmental, and Social Perspectives, eds S. Hofmann and P. DiBartolo (Amsterdam: Elsevier).

Leary, M. R., and Kowalski, R. M. (1995). "The self-presentation model of social phobia," in Social Phobia: Diagnosis, Assessment, and Treatment, eds R. G. Heimberg, M. R. Liebowitz, D. A. Hope, and F. R. Schneier (New York, NY: Guilford), 94-112.

Levinson, C. A., Langer, J. K., and Rodebaugh, T. L. (2013). Reactivity to exclusion prospectively predicts social anxiety symptoms in young adults. Behav. Ther. 44, 470-478. doi: 10.1016/j.beth.2013.04.007

Mallott, M. A., Maner, J. K., DeWall, N., and Schmidt, N. B. (2009). Compensatory deficits following rejection: the role of social anxiety in disrupting affiliative behavior. Depress. Anxiety 26, 438-446. doi: 10.1002/da.20555

Maner, J. K., DeWall, C. N., Baumeister, R. F., and Schaller, M. (2007). Does social exclusion motivate interpersonal reconnection? Resolving the "porcupine problem.” J. Pers. Soc. Psychol. 92, 42-55. doi: 10.1037/0022-3514.92.1.42

Maurage, P., Joassin, F., Philippot, P., Heeren, A., Vermeulen, N., Mahau, P., et al. (2012). Disrupted regulation of social exclusion in alcoholdependence: an fMRI study. Neuropsychopharmacology 37, 2067-2075. doi: 10.1038/npp.2012.54

Mendes, W. B., Major, B., McCoy, S., and Blascovich, J. (2008). How attributional ambiguity shapes physiological and emotional responses to social rejection and acceptance. J. Pers. Soc. Psychol. 94, 278-291. doi: 10.1037/0022-3514.94.2.278

Mineka, S., and Öhman, A. (2002). Phobias and preparedness: the selective, automatic, and encapsulated nature of fear. Biol. Psychiatry 52, 927-937. doi: 10.1016/S0006-3223(02)01669-4

Most, T., Amir, O., and Tobin, Y. (2000). The Hebrew vowel system: Raw and normalized acoustic data. Lang. Speech 43, 295-308. doi: 10.1177/00238309000430030401

Oakman, J., Gifford, S., and Chlebowsky, N. (2003). A multilevel analysis of the interpersonal behavior of socially anxious people. J. Pers. 71, 397-434. doi: 10.1111/1467-6494.7103006

Oaten, M., Williams, K. D., Jones, A., and Zadro, L. (2008). The effects of ostracism on self-regulation in the socially anxious. J. Soc. Clin. Psychol. 27, 471-504. doi: 10.1521/jscp.2008.27.5.471

Ohala, J. J. (1982). Physiological mechanisms underlying tone and intonation. In Fujisaki, Garding, Pre-prints working group on intonation (pp. 1-12). Paper presented in the13th International Congress of Linguists, Tokyo 1982.

Ohala, J. J. (1984). An ethological perspective on common cross-language utilization of F0 of voice. Phonetica, 41, 1-16. doi: 10.1159/000261706

Peterson, G. E., and Barney, H. L. (1952). Control methods used in a study of the vowels. J. Acoust. Soc. Am. 24, 175-184. doi: 10.1121/1.1906875

Powers, K. E., and Heatherton, T. F. (2012). Characterizing socially avoidant and affiliative responses to social exclusion. Front. Integr. Neurosci. 6:46. doi: 10.3389/fnint.2012.00046

Puts, D. A., Gaulin, S. J. C., and Verdolini, K. (2006). Dominance and the evolution of sexual dimorphism in human voice pitch. Evol. Hum. Behav. 27, 283-296. doi: 10.1016/j.evolhumbehav.2005.11.003

Puts, D. A., Hodges, C. R., Cárdenas, R. A., and Gaulin, S. J. C. (2007). Men’s voices as dominance signals: vocal fundamental and formant frequencies influence dominance attributions among men. Evol. Hum. Behav. 28, 340-344. doi: 10.1016/j.evolhumbehav.2007.05.002

Rapee, R. M., and Heimberg, R. G. (1997). A cognitive-behavioral model of anxiety in social phobia. Behav. Res. Ther. 35, 741-756. doi: 10.1016/S00057967(97)00022-3

Reijntjes, A., Thomaes, S., Boelen, P., van der Schoot, M., de Castro, B. O., and Telch, M. J. (2011). Delighted when approved by others, to pieces when rejected: children's social anxiety magnifies the linkage between self- and other-evaluations. J. Child Psychol. Psychiatry 52, 774-781. doi: 10.1111/j.14697610.2010.02325.x

Rochman, D., and Amir, O. (2013). Examining in-session expressions of emotions with speech/vocal acoustic measures: an introductory guide. Psychother. Res. J. Soc. Psychother. Res. 23, 381-393. doi: 10.1080/10503307.2013.784421

Ruscio, A. M. (2010). The latent structure of social anxiety disorder: consequences of shifting to a dimensional diagnosis. J. Abnorm. Psychol. 119, 662-671. doi: 10.1037/a0019341

Ruscio, A. M., Brown, T. A., Chiu, W. T., Sareen, J., Stein, M. B., and Kessler, R. C. (2008). Social fears and social phobia in the USA: results from the National Comorbidity Survey Replication. Psychol. Med. 38, 15-28. doi: 10.1017/S0033291707001699

Scherer, K. R. (1986). Vocal affect expression: a review and a model for future research. Psychol. Bull. 99, 143-165. doi :10.1037/0033-2909.99.2.143

Scherer, K. R., Johnstone, T., and Klasmeyer, G. (2003). Vocal Expression of Emotion. New York, NY: Oxford University Press. 433-456.

Sherbourne, C. D., Sullivan, G., Craske, M. G., Roy-Byrne, P., Golinelli, D., Rose, R. D., et al. (2010). Functioning and disability levels in primary care outpatients with one or more anxiety disorders. Psychol. Med. 40, 2059-2068. doi: 10.1017/S0033291710000176

Stroud, L. R., Tanofsky-Kraff, M., Wilfley, D. E., and Salovey, P. (2000). The Yale Interpersonal Stressor (YIPS): affective, physiological, and behavioral responses to a novel interpersonal rejection paradigm. Ann. Behav. Med. 22, 204-213. doi: 10.1007/BF02895115

Tai, K., Zheng, X., and Narayanan, J. (2011). Touching a teddy bear mitigates negative effects of social exclusion to increase prosocial behavior. Soc. Psychol. Pers. Sci. 2, 618-626. doi: 10.1177/1948550611404707

Tusing, K., and Dillard, J. (2000). The sounds of dominance. Vocal precursors of perceived dominance during interpersonal influence. Hum. Commun. Res. 26, 148-171. doi: 10.1111/j.1468-2958.2000.tb00754.x

Twenge, J. M., Baumeister, R. F., DeWall, C. N., Ciarocco, N. J., and Bartels, J. M. (2007). Social exclusion decreases prosocial behavior. J. Pers. Soc. Psychol. 92, 56-66. doi: 10.1037/0022-3514.92.1.56

Twenge, J. M., Baumeister, R. F., Tice, D. M., and Stucke, T. S. (2001). If you can't join them, beat them: effects of social exclusion on aggressive behavior. J. Pers. Soc. Psychol. 81, 1058-1069. doi: 10.1037/0022-3514.81.6.1058

Van Beest, I., and Williams, K. D. (2006). When inclusion costs and ostracism pays, ostracism still hurts. J. Pers. Soc. Psychol. 91, 918-928. doi: 10.1037/00223514.91.5.918

Wallace, S. T., and Alden, L. E. (1997). Social phobia and positive social events: the price of success. J. Abnorm. Psychol. 106, 416-424. doi: 10.1037/0021843X.106.3.416

Weeks, J. W. (2010). The disqualification of positive social outcomes scale: a novel assessment of a long-recognized cognitive tendency in social anxiety disorder. J. Anxiety Disord. 24, 856-865. doi: 10.1016/j.janxdis.2010.06.008

Weeks, J. W., Heimberg, R. G., and Heuer, R. (2011). Exploring the role of behavioral submissiveness in social anxiety. J. Soc. Clin. Psychol. 30, 217-249. doi: 10.1521/jscp.2011.30.3.217

Weeks, J. W., and Howell, A. N. (2012). The bivalent fear of evaluation model of social anxiety: further integrating findings on fears of positive and negative evaluation. Cogn. Behav. Ther. 41, 83-95. doi: 10.1080/16506073.2012.661452

Weeks, J. W., Lee, C.-Y., Reilly, A. R., Howell, A. N., France, C., Kowalsky, J. M., et al. (2012). "The Sound of Fear": assessing vocal fundamental frequency as a physiological indicator of social anxiety disorder. J. Anxiety Disord. 26, 811-822. doi: 10.1016/j.janxdis.2012.07.005

Wesselmann, E. D., Nairne, J. S., and Williams, K. D. (2012a). An evolutionary social psychological approach to studying the effects of ostracism. J. Soc. Evol. Cult. Psychol. 6, 309-328. doi: 10.1037/h0099249

Wesselmann, E. D., Wirth, J. H., Mroczek, D. K., and Williams, K. D. (2012b). Dial a feeling: detecting moderation of affect decline during ostracism. Pers. Individ. Dif. 53, 580-586. doi: 10.1016/j.paid.2012.04.039 
Wiggins, J. S. (1979). A psychological taxonomy of trait-descriptive terms: the interpersonal domain. J. Pers. Soc. Psychol. 37, 395-412. doi: 10.1037/00223514.37.3.395

Williams, K. D. (1997). Social Ostracism. New York, NY: Plenum Press.

Williams, K. D. (2001). Ostracism: The Power of Silence. New York, NY: Guilford Press.

Williams, K. D. (2009). Ostracism: A Temporal Need-Threat Model. San Diego, CA: Elsevier Academic Press. 275-314. doi: 10.1016/S0065-2601(08) 00406-1

Williams, K. D., Cheung, C. K. T., and Choi, W. (2000). Cyberostracism: Effects of being ignored over the Internet. J. Pers. Soc. Psychol. 79, 748-762. doi: 10.1037/0022-3514.79.5.748

Williams, K. D., and Zadro, L. (2005). Ostracism: The Indiscriminate Early Detection System New York, NY: Psychology Press, 19-34.

$\mathrm{Xu}$, J., and Roberts, R. E. (2010). The power of positive emotions: it's a matter of life or death-Subjective well-being and longevity over 28 years in a general population. Health Psychol. 29, 9-19. doi: 10.1037/a0016767

Zadro, L., Boland, C., and Richardson, R. (2006). How long does it last? The persistence of the effects of ostracism in the socially anxious. J. Exp. Soc. Psychol. 42, 692-697. doi: 10.1016/j.jesp.2005.10.007

Zadro, L., Williams, K. D., and Richardson, R. (2004). How low can you go? Ostracism by a computer is sufficient to lower self-reported levels of belonging, control, self-esteem, and meaningful existence. J. Exp. Soc. Psychol. 40, 560-567. doi: 10.1016/j.jesp.2003.11.006

Zuckerman, M., Larrance, D. T., Spiegel, N. H., and Klorman, R. (1981). Controlling nonverbal displays: facial expressions and tone of voice. J. Exp. Soc. Psychol. 17, 506-524. doi: 10.1016/0022-1031(81)90037-8

Conflict of Interest Statement: The authors declare that the research was conducted in the absence of any commercial or financial relationships that could be construed as a potential conflict of interest.

Received: 20 August 2013; accepted: 27 February 2014; published online: 18 March 2014

Citation: Gilboa-Schechtman E, Galili L, Sahar Y and Amir O (2014) Being "in" or "out" of the game: subjective and acoustic reactions to exclusion and popularity in social anxiety. Front. Hum. Neurosci. 8:147. doi: 10.3389/fnhum.2014.00147 This article was submitted to the journal Frontiers in Human Neuroscience. Copyright (C) 2014 Gilboa-Schechtman, Galili, Sahar and Amir. This is an openaccess article distributed under the terms of the Creative Commons Attribution License (CC BY). The use, distribution or reproduction in other forums is permitted, provided the original author(s) or licensor are credited and that the original publication in this journal is cited, in accordance with accepted academic practice. No use, distribution or reproduction is permitted which does not comply with these terms. 